\title{
Design and Research of Grinder Cooling Device Used for Mechanical Numerical Control Machining
}

\author{
Yan Cheng \\ Zibo Vocational Institute Zibo, Shandong 255314, China
}

\begin{abstract}
This paper introduces design method and working principle of grinder cooling device for mechanical numerical control machining. By analyzing the problems of grinder cooling in mechanical numerical control machining, technical solutions for the problems, model construction and specific implementation pattern are proposed. Compared with the traditional cooling device, this device is simple to use, uniform in cooling, and has better coolant cooling effect. While cooling, it removes a part of metal chips and impurities, avoiding adverse effect on accuracy of the machined surface, which provides important guidance for production practice.
\end{abstract}

Keywords: Numerical control machining, grinder, cooling device, roughness

\section{Introduction}

Domestic grinders are mostly based on model equipment. When the grinder is used in a mass flow production line, regarding cooling flow of the workpiece, effect of cooling water filtration, whether the iron filings and sand particles on the machine tool can be washed away in time, and whether the iron filings and sand particles in the cooling tank can be removed in time, the grinder imposes high requirements for the chip removal cooling device, which reflects the importance of chip removal cooling device at this time. Therefore, various chip removal cooling devices designed according to actual needs continue to appear, such as: cooling devices with magnetic separators and scrapers for chip removal, chip removal cooling devices with non-woven filtration, and other chip removal cooling devices with automatic filtration, automatic cleaning, automatic chip removal functions. Due to the different focuses on cost, function and practicability, chip removal cooling device has respective characteristics. At present, there are two basic forms of chip removal cooling devices by domestic grinder manufacturers: one is the natural precipitation type (see Figure 1); the other is the scraper type (see Figure 2).

\section{Problems in Grinder Cooling Device}

In the machining process, various technological methods are needed, such as turning, milling, planing, grinding, etc. To reduce the roughness in machining and improve machining accuracy, grinding is usually adopted to improve flatness of the machined surface. In the grinding process, to improve the machining efficiency and accuracy, grinder is often used for machining. During the machining, due to the extremely high-speed relative movement between the grinding wheel and the blank, the machined surface temperature rises sharply, while temperature of the rest part of the blank is relatively low, so the blank deforms under the uneven temperature, which affects the machining effect. At the same time, too high temperature will also affect the mechanical properties of the blank, which goes against the follow-up use of the machine parts.

\subsection{Problem description}

At present, the use of some commonly used surface grinders and vertical grinders often involves a large workbench. After the workbench is energized, a strong magnetic force will be generated to firmly absorb the blank to the workbench, thus avoiding blank movement. However, the grinding wheel will move to grind the machined surface of the blank. During this period, a coolant pipe will be guided to the inclined top of the blank to spray coolant and cool the machined surface. Nonetheless, the method of spraying coolant from the coolant pipe has a limited range of action. It can only directly cool a small area, and the rest can only be cooled by the gradual flow of the coolant,

ISSN: 0010-8189

(C) CONVERTER 2020

www.converter-magazine.info 
which cannot guarantee the uniformity of cooling during the blank machining, so machining effect is affected to a certain extent.

Existing coolant is pumped from the coolant tank for use. The used coolant will flow into the coolant tank again. After repeated use in this way, the coolant will contain more metal powder and various impurities, which will damage the machined surface and affect the machining effect if it is sprayed on the blank. In addition, after the coolant in the existing coolant tank is used uninterrupted for a long time, due to the lack of sufficient energy exchange with the outside, a certain temperature rise will occur, which reduces the cooling effect of the coolant.

\subsection{Problem analysis}

To solve the above problems, this paper proposes a grinder cooling device for mechanical numerical control machining, which is possible to achieve relatively uniform cooling of the blanks during the machining process and good cooling effect of the coolant. At the same time, it removes a part of metal chips and impurities, thus avoiding negative impact on the machining effect of the machined surface.

Such grinder cooling device used for mechanical numerical control machining consists of cooling tank, cooling nozzle, circulating pump, coolant tank, air pump, magnet, sponge, etc. The blank is placed in the middle of the cooling tank. As the circulating pump starts, the coolant is sprayed through the cooling tank inlet. As the cooling tank is cylindrical, the coolant will rotate rapidly in the cooling tank to speed up the liquid flow and cool the blank. As the coolant increases, the liquid level in the cooling tank rises and gradually submerges the blank, so that overall cooling of the blank is possible. As the coolant temperature rises, the density will decrease. The upper coolant in the cooling tank has relatively high temperature. With the increase of coolant, hotter coolant will flow out from the cooling tank outlet, and the heat generated by grinding will be taken away during the continuous inflow and outflow, so that the blank temperature during the machining will not be so high as to affect the machining effect. At the same time, the cooling nozzle can be rotated at any position and angle. By spraying coolant to the key positions of the blank, key part cooling is possible, which further improves the cooling effect. The coolant flowing out of the cooling tank enters the coolant tank, the magnet will adsorb the iron filings in the coolant, and the sponge will filter the impurities in the coolant to ensure cleanness of the coolant. The air pump will blow air into the cooling tank, so that the coolant in the coolant tank "boils", which speeds up the loss of heat carried in the coolant, and avoids the overall temperature rise of the coolant during long-term use.

\section{Design of Grinder Cooling Device for Mechanical Numerical Control Machining}

\subsection{Technical solution}

The grinder cooling device for mechanical numerical control machining consists of cooling tank, cooling nozzle, circulating pump, coolant tank, air pump, magnet, and sponge. For its features, the cooling tank is a cylindrical tank, which has cooling tank inlet and cooling tank outlet in the tangential direction. The outer side of the cooling tank has a track along the circumference. A cooling nozzle is connected to the track, which can slide on the latter. The cooling nozzle is long flat nozzle; the coolant tank is divided into three parts, namely purification zone, cooling zone, and standing zone. The purification zone connects with the lower part of the cooling zone, the cooling zone connects with the upper part of the standing zone. The upper part of the purification zone has a coolant tank inlet, and the purification zone has magnet and sponge. The lower part of the standing zone has a coolant tank outlet connected with a circulating pump, and an air pump is arranged under the coolant tank. The air pump is connected to the bottom of the cooling zone with air pipe. The circulating pump pipeline is connected to the inlet of the coolant tank, and the outlet pipeline of the coolant tank is connected to the inlet of the coolant tank and the cooling nozzle. The cooling tank inlet is close to the bottom of the cooling tank, the cooling tank outlet is close to the upper opening of the cooling tank, and there is a height difference between the two. The cooling nozzle can be bent at any angle. In the purification zone, the magnet is not in contact with the sponge, and the magnet is above the sponge, while the sponge is above the part connected with the cooling zone. There is a one-way valve on ISSN: 0010-8189 
the pipeline between the air pump and the cooling tank, and the cooling tank occupies an area larger than the working range of the grinder.

3.2 Model construction

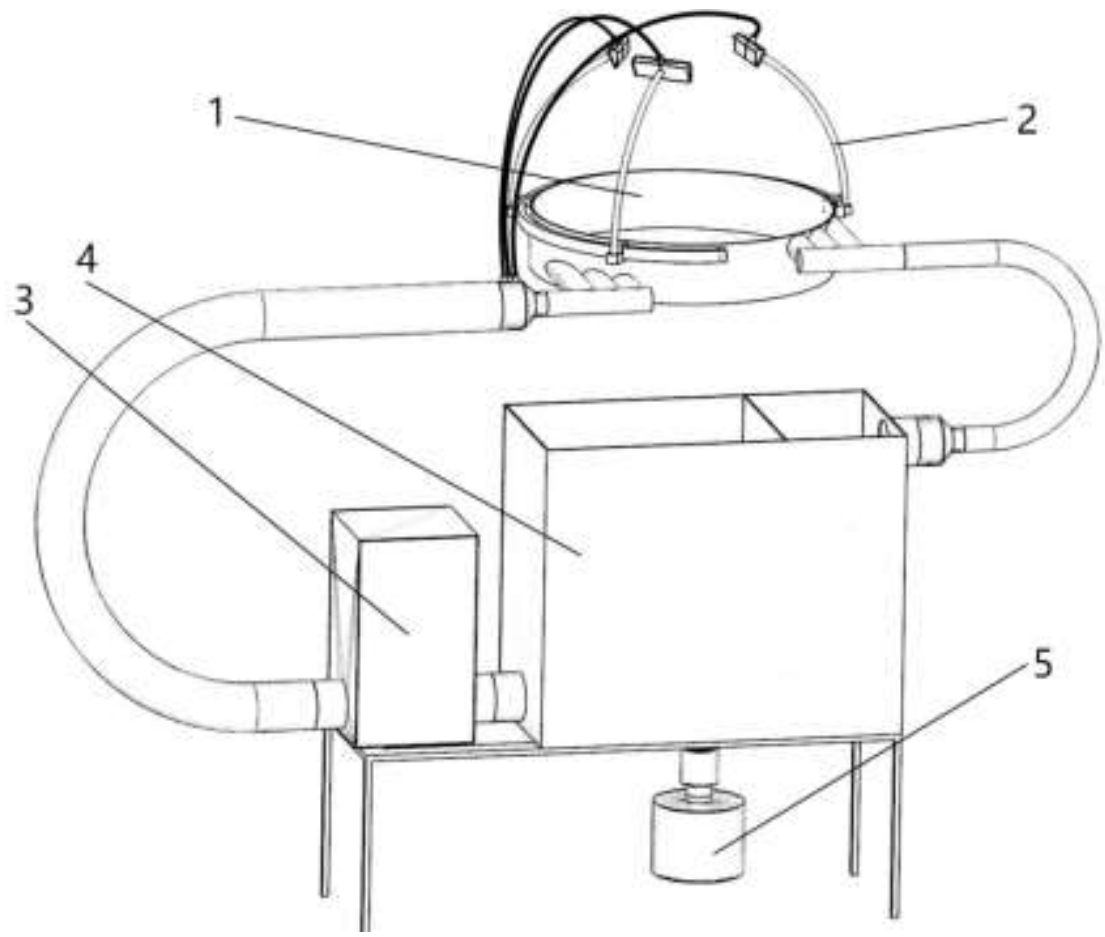

Figure 1 Schematic diagram of the structure

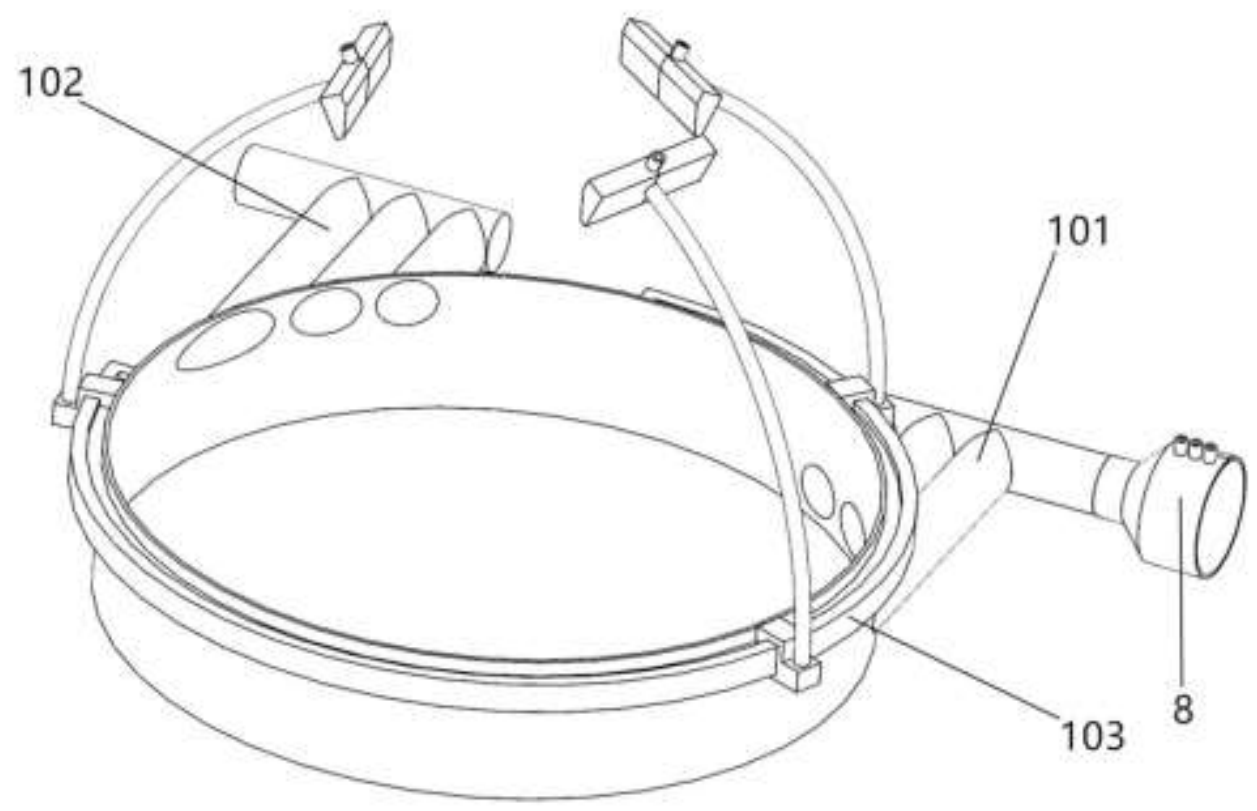

Figure 2 Schematic diagram of the cooling tank structure 


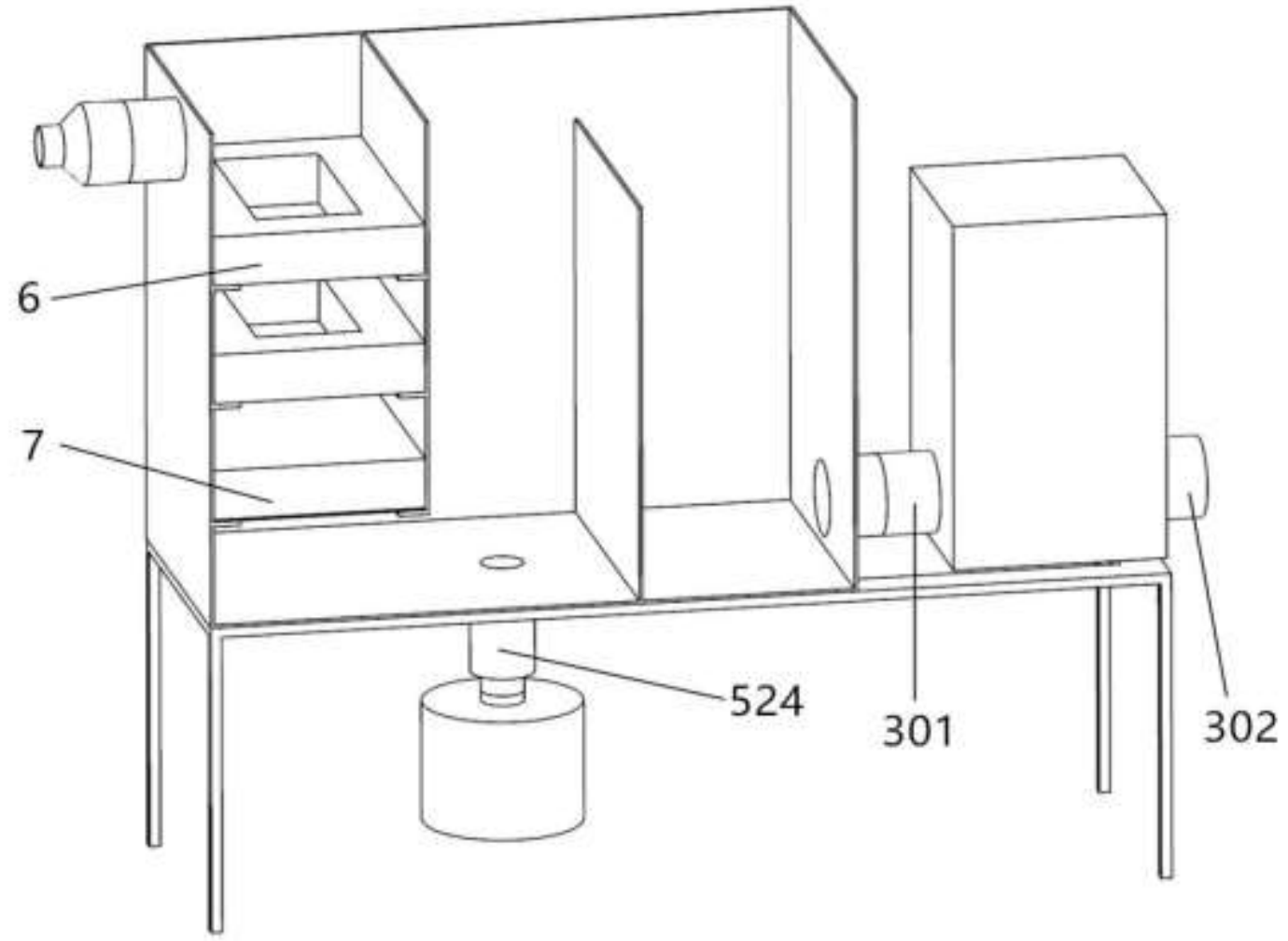

Figure 3 Schematic diagram of the coolant tank structure

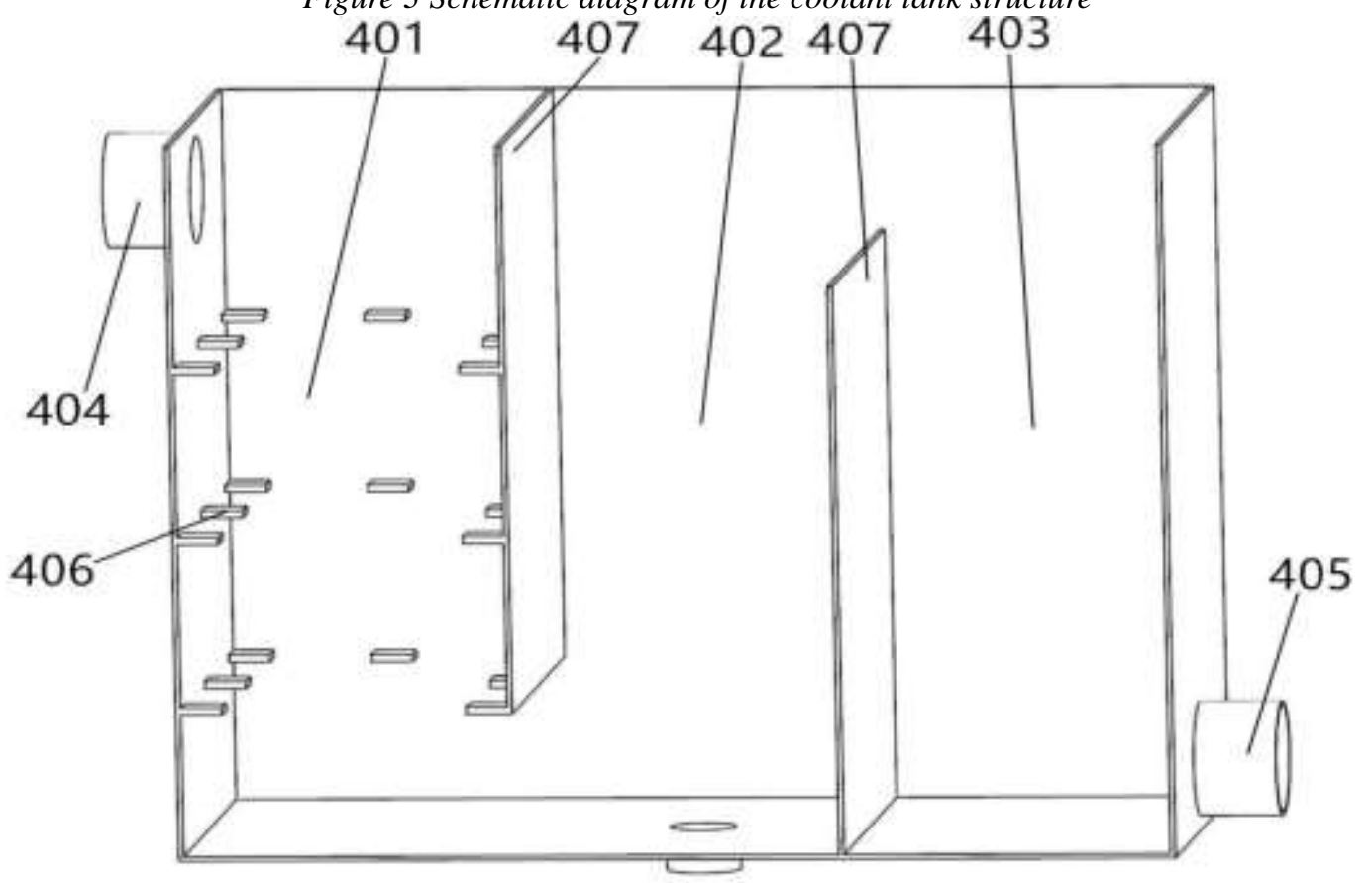

Figure 4 Schematic diagram of the structure of the new coolant tank 


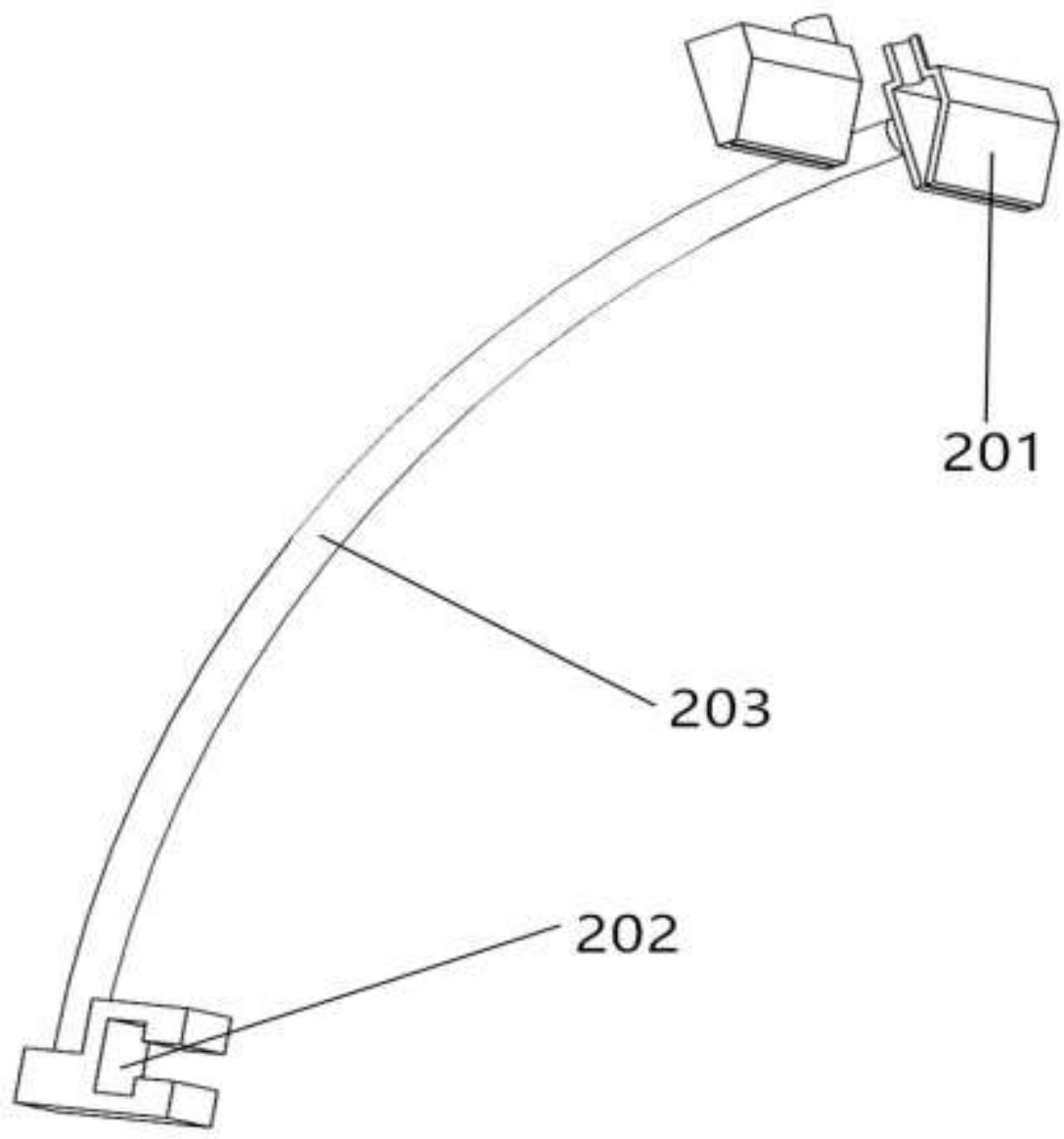

Figure 5 Schematic diagram of the cooling nozzle structure

Where: 1 cooling tank, 2 cooling nozzle, 3 circulating pump, 4 coolant tank, 5 air pump, 6 magnet, 7 sponge, 8 branch pipe, 101 cooling tank inlet, 102 cooling tanks outlet, 103 track, 201 nozzle, 202 groove, 203 connecting rod, 301 circulation pump inlet, 302 circulation pump outlet, 401 purification zone, 402 cooling zone, 403 standing zone, 404 coolant tank inlet, 405 coolant tank outlet, 406 shelf, 407 partition, 524 one-way valve.

\subsection{Implementation}

The following describes the embodiments of the device in detail with reference to the model diagram. In the description herein, it should be understood that the orientation or positional relationship indicated by the terms "upper", "lower", "left", "right", "front", "back", "vertical" and "horizontal" is based on the orientation or positional relationship shown in the drawings, which is used only to facilitate and simplify description, and does not indicate or imply that the mentioned device or element must have a specific orientation or is configured and operated in a specific orientation. As shown in Figures 1-5, the grinder cooling device herein for mechanical numerical control machining consists of cooling tank 1 , cooling nozzle 2 , circulating pump 3, coolant tank 4, air pump 5, magnet 6 , and sponge 7. For its features, the cooling tank 1 is a cylindrical tank, which has cooling tank inlet 101 and cooling tank outlet 102 in the tangential direction. The outer side of the cooling tank 1 has a T-shaped track 103 along the circumference side. Track 103 is a three-quarter circle, with baffles at both ends of the track 103. A cooling nozzle 2 is connected to track 103, and a T-shaped groove 202 is provided at the lower end of cooling nozzle 2 . The cooling nozzle 202 can slide on the track 103. The cooling nozzle 2 is long flat nozzle 201. A connecting rod 203 connects the groove 202 and the nozzle 201. Coolant tank 4 is a cube tank, which is divided into three parts by the partition 407, namely purification zone 401, cooling zone 402, and standing zone 403. The purification zone 401 connects with the lower part of the cooling zone 402, the cooling zone 402 connects with the upper part of the standing zone 403. The upper part of the purification zone 401 has a coolant tank inlet 404 . The purification zone

ISSN: 0010-8189

(C) CONVERTER 2020 
401 is arranged with three groups of shelves 406. There are two square magnets 6 and a sponge 7 in the purification zone 401. The magnet 6 and the sponge 7 are placed on the shelf 406. The lower part of the standing zone 403 has a coolant tank outlet 405 connected with circulating pump inlet 301 of circulating pump 3, and an air pump 5 is arranged under the coolant tank 4. The outlet of the air pump 5 is connected to the bottom of the cooling zone 402 with air pipe. The circulating pump outlet 302 of the circulating pump 3 is connected to the branch pipe 8 through a pipeline, one outlet of the branch pipe 8 is connected to the cooling tank inlet 101, and the remaining outlet pipes of the branch pipe 8 are connected to the cooling nozzle 2 . The cooling tank outlet 102 is connected to the inlet 404 of the coolant tank via pipeline. With the operation of the circulating pump 3 , the coolant in the coolant tank 4 is pressurized by the circulating pump 3 and enters the cooling tank 1 through the cooling tank inlet 101 and the cooling nozzle 2, which flows out from the cooling tank outlet 102 to enter the coolant tank 4 again. Through magnet 6 and sponge 7, impurities are removed, and the air pump 5 operates to add air to the coolant for cooling effect. The cooling tank inlet 101 is close to the bottom of the cooling tank 1 , the cooling tank outlet 102 is close to the upper opening of the cooling tank 1, and there is a height difference between the two, so that the coolant can rotate in the cooling tank 1 for a sufficient number of times to enhance the contact with the blank. The connecting rod 203 is made of aluminum alloy with strong plasticity, so that the cooling nozzle 2 can be bent at any angle, which increases the spray coverage of the coolant. In the purification zone 401, the magnet 6 is not in contact with the sponge 7 , and the magnet 6 is above the sponge 7 , while the sponge 7 is above the part connected with the cooling zone 402, so that iron filings are absorbed first, and then the remaining impurities are filtered to facilitate secondary recovery of iron filings, which reduces the cleaning and replacement cycle of the sponge 7 . There is a one-way valve 524 on the pipeline between the air pump 5 and the coolant tank 4 , so that the gas generated by the air pump 5 can enter the coolant tank 4, while the coolant in the coolant tank 4 will not flow back into the air pump 5. The cooling tank 1 occupies an area larger than the working range of the grinder, so that the cooling tank 1 will not interfere with the grinder or cause damage.

\subsection{Working principle}

Before use, place the cooling tank 1 on the grinder workbench, place the blank in the center of the cooling tank 1 , turn on the power of the grinder machining platform, so that the electromagnet will absorb the cooling tank 1 and the blank to the grinder workbench, thus avoiding movement of the blank. By adjusting the spray position of the cooling nozzle 2 , the coolant sprayed by the cooling nozzle 2 can cover some important positions requiring cooling on the blank without affecting the rotation of the grinding wheel. In use, during the grinding process of the grinder, the circulating pump 3 is started, and the circulating pump 3 will extract the coolant from the coolant tank 4 and transport it along the pipeline to the branch pipe 8 . Part of the coolant will reach the nozzle 2 along the pipeline and be sprayed from the nozzle 201 onto the blank. Another part of the coolant will enter the cooling groove 1 from the cooling groove inlet 101. Since the cooling groove 101 is circular, the coolant will rotate and elevate in the cooling groove 1 to cool the blank in all directions. Plus cooling of key part by the nozzle 2, the blank can be well cooled. As the liquid level in the cooling tank 1 rises, the coolant in the cooling tank 1 flows out from the cooling tank outlet 2 and flows into the coolant tank 4 along the pipeline. The coolant first enters the purification zone 401. The magnet 6 and sponge 7 in the purification zone 401 will absorb iron filings and filter impurities of the inflowing coolant. As the coolant continuously flows into the cooling zone 402, the air pump continuously runs to inject gas into the cooling zone 402, so that the coolant in the cooling zone 402 is in a "boiling" state, thereby carrying away partial heat of the coolant and lowering the coolant temperature. The coolant continues to flow into the standing zone 403. The coolant in the standing zone 403 is not treated in any way, so that the coolant maintains a stable state and can be easily sucked by the circulating pump 3, thus avoiding damage caused by excessive gas in the coolant sucked by the circulating pump 3. In this way, the next round of coolant circulation is possible. It is noteworthy that the fixed connection and fixed installation should be understood in a broad sense unless otherwise clearly specified and limited. For example, it may be welding, gluing, or integral molding and other common practices well known to those skilled in the art.

\section{Conclusion}

ISSN: 0010-8189

(C) CONVERTER 2020 
Compared with the existing cooling device, due to the contact with the blank by immersion rotation, more heat can be taken away from the blank, and the cooling is more uniform, which avoids uneven cooling speed distribution and the resulting slight deformation of the blank due to the direct injection of coolant by the existing cooling device. At the same time, the long flat nozzle can achieve a large range of local spray cooling, which facilitates cooling in key areas of the blank. The magnet and sponge can be used for impurity removal and filtration of coolant, which avoids the impact of impurities on the grinding effect and reduces the coolant replacement frequency. The use of air pump to cool the coolant can reduce the rate of coolant temperature rise to a certain extent, avoiding weakening of the cooling effect caused by the overall temperature rise of the coolant during the long-term use. The device is convenient and simple to use, with stable and uniform cooling speed. Moreover, the coolant has long single use cycle, and the overall effect is desirable.

\section{References}

[1] B. M. Brzhozovskll, V. V. Martynov, E. S. Pleshakova, "Reliability of modified".

[2] “Cutting tools,” Russian Engineering Research, vol. 4, no. 12, pp. 769-772, 2015.

[3] D. Kerr, J. Pengilley, R. Garwood, "Assessment and visualisation of machine tool wear using computer vision," International Journal of Advanced Manufacturing Technology, vol. 28, no. 7-8, pp. 81-791, 2006.

[4] W. Kuo, “An annotated overview of system-reliability optimization," IEEE Transactions on Reliability, vol. 49, no. 2, pp. 176-187, 2000.

[5] G. X. Shen, Y. Z. Zhang, Y. X. Xue, et al., "Comprehensive evaluation of the reliability of CNC machine tools based on entropy weight method," Journal of Jilin University: Engineering Edition, vol. 39, no. 5, pp. 1208-1211, 2009.

[6] W. Z. Liao, E. S. Pan, L. F. Xi, "Dynamic preventive maintenance strategy based on equipment reliability," Journal of Shanghai Jiaotong University, vol. 43, no. 8, pp. 1332-1336, 2009.

[7] Y. Zhao, J. Yang, X. B. Ma, "Reliability data analysis course," Beijing: Beijing University of Aeronautics and Astronautics Press, 2009.

[8] G. X. Shen, S. Meng, Y. Z. Zhang, et al., "Application of mean rank order in subsystem reliability modeling," Journal of Jilin University: Engineering Edition, vol. 44, no. 1, pp. 101-105, 2014.

[9] L. Q. Zou, "The principle of least squares and its simple application," Science \& Technology Information, vol. 23, pp. 282-283, 2010.

[10] Y. Z. Zhang, G. X. Shen, S. Wu, et al., "Three-parameter Weibull distribution model for randomly truncated CNC machine tools," Journal of Jilin University: Engineering Edition, vol. 39, no. 2, pp. 378-381, 2009.

[11] S. Q. Zhang, "Discussion on the goodness of fit index of curve regression," Chinese Journal of Health Statistics, vol. 19, no. 1, pp. 9-11, 2002.

[12] R. Y. Ronald, “A fuzzy measure approach to systems reliability modeling," IEEE Transactions on Fuzzy Systems vol. 22, no. 5, pp. 1139-1150, 2014.

[13] Y. J. Liu, J. W. Fan, Y. Li, "Reliability modeling and assessment of CNC grinding machine," Quality, Reliability, Risk, Maintenance, and Safety Engineering (QR2MSE), no. 7, pp. 95-98, 2003.

[14] Q. Z. Zhao, L. P. Wang, J. J. Wang, “Analysis and research on reliability test and evaluation technology of CNC machine tool,” Manufacturing Technology \& Machine Tool, no. 11, pp. 17-21, 2017.

[15] X. C. Zhu, B. B. Xu, J. L. Wang, et al., "Comprehensive evaluation of the reliability of CNC machine tools based on rough fuzzy rules," Tool Engineering, vol. 49, no. 9, pp. 14-19, 2015.

[16] P. L. Chen, X. F. Yue, J. Liang, “The principles and maintenance of freezing and air conditioning," Light Industry Publishing House, Co-editor, Handbook on Modulation and Cooling Techniques, Tongji University Publishing House, 1990.

[17] J. C. Fu, "Principles and crafts," Editor-in-Chief, Hunan University Publishing House, 1st edition, August 1986. S. G. Xiao, "The final knife material and its reasonable selections," Mechanical Industry Press, 1st edition, August 1981.

[18] Y. M. Wang, J. H. Zhou, D. Wu, et al., "Research on the deformation of $60 \mathrm{~kg} / \mathrm{m}$ rail in the four-roller

ISSN: 0010-8189

(C) CONVERTER 2020 
universal pass," Steel Rolling, vol. 25, no. 5, pp. 26, 2008.

[19] P. Li, L. Y. Zhou, Z. W. Liang, et al., "Trial production of American standard SS310HB rail," Steel Rolling, vol. 35, no. 1, pp. 42, 2018.

[20] “TB/T2304-2012 43kg/m 75kg/m technical specification for rail order". 